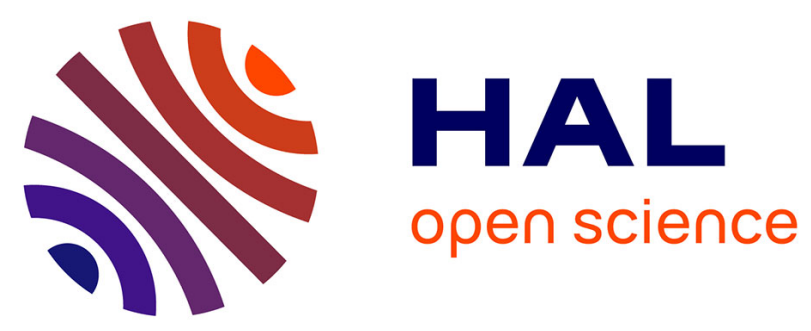

\title{
De Pipas Y Sustancias: Costumbres Fumatorias Durante El Periodo Formativo En El Litoral Del Desierto De Atacama (Norte De Chile)
}

Carolina Carrasco, Javier Echeverria, Benjamin Ballester, Hermann Niemeyer

\section{- To cite this version:}

Carolina Carrasco, Javier Echeverria, Benjamin Ballester, Hermann Niemeyer. De Pipas Y Sustancias: Costumbres Fumatorias Durante El Periodo Formativo En El Litoral Del Desierto De Atacama (Norte De Chile). Latin American Antiquity, 2015, 26 (2), pp.143-161. 10.7183/1045-6635.26.2.143 . hal02516502

\author{
HAL Id: hal-02516502 \\ https://hal.science/hal-02516502
}

Submitted on 12 Jun 2020

HAL is a multi-disciplinary open access archive for the deposit and dissemination of scientific research documents, whether they are published or not. The documents may come from teaching and research institutions in France or abroad, or from public or private research centers.
L'archive ouverte pluridisciplinaire HAL, est destinée au dépôt et à la diffusion de documents scientifiques de niveau recherche, publiés ou non, émanant des établissements d'enseignement et de recherche français ou étrangers, des laboratoires publics ou privés. 


\title{
DE PIPAS Y SUSTANCIAS: COSTUMBRES FUMATORIAS DURANTE EL PERIODO FORMATIVO EN EL LITORAL DEL DESIERTO DE ATACAMA (NORTE DE CHILE)
}

\author{
Carolina Carrasco, Javier Echeverría, Benjamín Ballester y Hermann M. Niemeyer
}

\begin{abstract}
El hallazgo de pipas en contextos fúnebres del litoral del Desierto de Atacama hace más de un siglo, ha sido la base para sugerir que los grupos de pescadores, cazadores y recolectores marinos tuvieron como costumbre fumar durante el período Formativo (1500 a.C.-1000 cal d.C.). Lo que seguía siendo una incógnita es qué estaban fumando y de dónde provenían las sustancias consumidas. En la búsqueda de dar solución a este problema, presentamos el análisis de los residuos adheridos de cuatro pipas de piedra en forma de T invertida, recuperadas de un cementerio de la costa del Desierto de Atacama al norte de Chile, usando dos metodologías complementarias derivadas de la arqueobotánica y la química. Paralelamente, realizamos un análisis químico sobre cabello humano perteneciente a un individuo asociado a una de las pipas. Se logró identificar, al interior de éstas, la presencia de nicotina y otras sustancias, tales como microrrestos de Nicotiana y de otras especies, además de nicotina, en el cabello muestreado. Finalmente, discutimos estos resultados en función de la disponibilidad de fuentes de estos recursos, estrategias de movilidad, relaciones de intercambio y el modo de vida de las poblaciones litorales.
\end{abstract}

Smoking pipes found in funerary contexts on the Atacama Desert coast suggest that the custom of smoking was widespread among hunter-gatherers and fishermen during the Formative (1500 B.C.- cal A.D. 1000). The substances smoked and their provenience have remained unknown until now. This knowledge is essential for understanding smoking as part of the functioning and the reproduction of social groups among these early coastal populations. Here we report on the archaeobotanical and chemical analysis of internal residue from four inverted-T lithic pipes recovered from a cemetery near the coastal city of Antofagasta, in northern Chile. We also carried out chemical analyses of human hair belonging to one of the individuals with whom the pipes had been interred. Analysis of residue from inside the pipes revealed the presence of nicotine and other substances, as well as micro-remains of Nicotiana and other plant species. Nicotine was also detected in the hair sample from the buried individual. We discuss the implications of these results for understanding the availability of resources and the mobility strategies, exchange relationships, and lifestyles of these littoral communities.

A principios del siglo veinte, Augusto Capdeville durante las excavaciones de algunos cementerios en la costa de Taltal, en el litoral del Desierto de Atacama, al norte de Chile, recuperó un conjunto de artefactos que inmediatamente llamaron su atención por su rareza y singularidad. Se trataba de pipas, una tubular y otras con el hornillo perpendicular al tubo, en forma de T invertida. En su correspondencia con el arqueólogo alemán Max Uhle, en 1918 relata que en la excavación del cementerio de Puntilla
Sur, "a esa profundidad de un metro, en un punto, se halló la pipa tubular de piedra, que a mí me pareció aún tenía un fuerte olor a tabaco" (Mostny 1964:67). En otra de sus cartas Capdeville narra que de las pipas en forma de T invertida recuperadas de otros cementerios creyó "percibir en el hornillo, un vago olor a tabaco, o algo parecido (...) [y que] el hornillo, por dentro, tiene incrustaciones de una sustancia blanca amarillenta, algo sucia” (Mostny 1964:47). En ese momento, ninguno de los dos investigadores puso

Carolina Carrasco — Monjitas 537, Santiago, Chile (carolina.carrasco.lagos@ gmail.com)

Javier Echeverría y Hermann M. Niemeyer - Departamento de Ciencias Ecológicas, Facultad de Ciencias, Universidad de Chile, Casilla 653, Santiago, Chile (echeverria@abulafia.ciencias.uchile.cl; niemeyer@abulafia.ciencias.uchile.cl) Benjamín Ballester — Museo de Antofagasta, Simón Bolívar 188, Antofagasta, Chile (benjaminballesterr@gmail.com)

Latin American Antiquity 26(2), 2015, pp. 143-161

Copyright (C) 2015 by the Society for American Archaeology

DOI: 10.7183/1045-6635.26.2.143 
en duda esas aseveraciones, cargadas de intuición y basadas en la experiencia directa, así como sustentadas en la relación forma-función de los artefactos.

Hoy, a casi cien años de esta discusión epistolar, el problema de las pipas y las costumbres fumatorias de los antiguos habitantes del litoral del Desierto de Atacama sigue siendo una incógnita. Intentando contribuir dentro de este escenario es que presentamos el estudio de un conjunto de pipas de piedra en forma de $\mathrm{T}$ invertida ofrendadas a un grupo de cazadores-recolectores marinos de Antofagasta y del mismo período que las registradas por Augusto Capdeville en 1918, esta vez utilizando procedimientos metodológicos y técnicos derivados de ciencias auxiliares a la arqueología que permitan comprender de forma más certera su uso. Este contexto es único a nivel internacional, ya que ofrece múltiples líneas de evidencias y un amplio potencial de análisis para comprender la práctica fumatoria, presentando pipas con residuos, contextos fúnebres bien registrados, información bioantropológica y restos de cabello humano para verificar el consumo directo de sustancias.

Se implementó un análisis de residuos adheridos desde dos líneas paralelas: (1) la química, que a través de la cromatografía de gases acoplada a espectrometría de masas (CG-EM) ha demostrado ser una herramienta confiable para la detección de compuestos químicos presentes en cantidades trazas en matrices arqueológicas (Echeverría et al. 2014; Rafferty 2002, 2006; Rafferty et al. 2012; Tushingham et al. 2013); y (2) la arqueobotánica, que mediante el análisis microscópico (microfósiles) y macroscópico (semillas, maderas y carbones) ha entregado un cuerpo robusto de datos para dilucidar preguntas relacionadas con la funcionalidad de los artefactos (Loy 1994; Musaubach y Berón 2012; Piperno y Holst 1998; Planella et al. 2011, 2012; Quiroz et al. 2012).

En el pasado, las distintas comunidades que habitaban en el Desierto de Atacama, desde la costa del Pacífico hasta la vertiente oriental de Los Andes, se encontraban insertas dentro de una red de relaciones donde circulaban ideas, bienes y personas. Cada una contaba con particularidades en su modo de vida, expresiones culturales y experiencias cotidianas, que la hacía distinta a sus vecinos y a la vez única, heredera de su pasado y agente históricos cargado de posibilidades innovadoras. Dentro de este contexto, el fumar durante el período Formativo (1500 a.C.-1000 cal d.C.) fue una costumbre extendida, pero que cada localidad nutrió con sus propios matices y sutilezas, según sus realidades históricas y sociales. Al menos así queda en evidencia al examinar las pipas de los contextos arqueológicos del Formativo (Agüero et al. 2006; Berenguer et al. 1986; Capdeville 1928; Le Paige 1964, 1974; Mostny 1964; Núñez et al. 2005, 2006; Orellana 1963, 1991; Sinclaire 2004; Tarragó 1989; Thomas 1995; Thomas et al. 1989-1990; Torres 1996, 1998; Torres et al. 1991; Torres-Rouff, Pimentel y Ugarte 2012; Westfall 1993-1994).

El caso de los grupos litorales del Formativo es sólo un ejemplo, ya que de todo el desierto fueron quienes más se aferraron al tradicional modo de vida cazador-recolector y los únicos que basaron su economía en el mar. Por esto, que desde su singularidad social y adaptativa se podrá reflexionar en torno a sus propias soluciones y estrategias tecnológicas y culturales relativas al fumar; una base para poder generar comparaciones con el resto del Desierto de Atacama y sus regiones vecinas en el futuro.

\section{El Vertedero Municipal de Antofagasta: Antecedentes Sociales, Contexto Arqueológico y Pipas}

Durante el Formativo costero (1500 a.C.-1000 cal d.C.) ocurren transformaciones sociales trascendentales en el delineamiento de la estructura económica y política de la sociedad del Desierto de Atacama, cimentando las bases y forjando las alianzas de la sociedad a la que se enfrentaron 500 años después los primeros europeos. Las innovaciones y nuevos desarrollos se manifestaron en cada campo de lo social, desde sus esferas productivas y tecnológicas, hasta sus complementos representacionales, simbólicos, artísticos y rituales, dando origen a nuevas subjetividades y formas de experiencia social. Si bien cada localidad siguió procesos propios según sus realidades, en general en todo el desierto las economías se consolidaron como excedentarias y orientadas al intercambio.

En los valles, quebradas y oasis del interior, las economías se vertieron hacia el pastoralismo, la recolección de frutos y la agricultura, mientras 


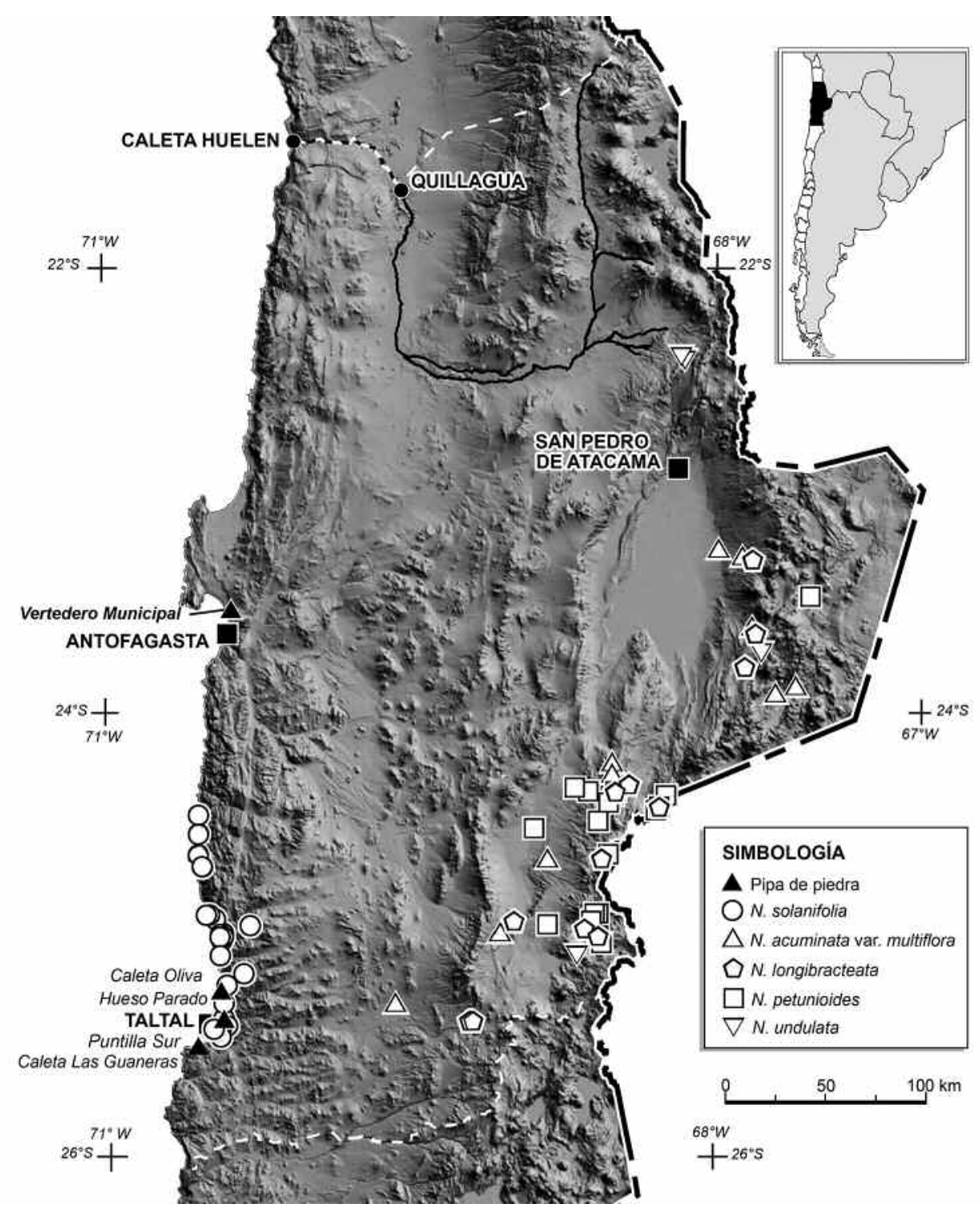

Figura 1. Mapa de la ubicación del cementerio de EI Vertedero Municipal de Antofagasta y los sitios arqueológicos donde se han recuperado pipas de piedra en " $T$ " invertida (nombres en letras cursivas). Se señala además la referencia geográfica de las colectas de especies del género Nicotiana de la región existentes en los principales herbarios de Chile (Universidad de Concepción y Museo Nacional de Historia Natural).

que sus desarrollos tecnológicos se diversificaron, alcanzando niveles inéditos con contenedores cerámicos, nuevos dispositivos de caza, sofisticadas vestimentas y textiles, metalurgia y minería, además de una enorme industria de adornos corporales como turbantes, gorros, collares, brazaletes, aros, colgantes y tembetás, que junto a la deformación craneana materializaron en los individuos las diferencias identitarias y culturales entre las distintas colectividades (Agüero 1994; Agüero y
Cases 2004; Agüero et al. 2006; Ayala 2001; Cartajena 1994; Cartajena et al. 2007; de Souza 2004; Gallardo 1993; Gallardo y de Souza 2008; Gallardo y Yacobaccio 2005; Montt 2002; Núñez 2005; Núñez et al. 2005, 2006; Rees 1999; Rees y de Souza 2004; Sinclaire 2004; Uribe 2009; Uribe y Ayala 2004).

En la costa, este escenario fue personificado por comunidades especializadas en la caza, pesca y recolección marina, que habitaban en residencias 
estables, desde donde articulaban un extenso territorio gracias a sus embarcaciones y al desplazamiento pedestre a través de la cordillera de la costa y la pampa (Ballester y Clarot 2014; Ballester y Gallardo 2011; Cases et al. 2008; Knudson et al. 2012; Llagostera 1979, 1990; Pimentel 2012; Pimentel et al. 2011; Torres-Rouff, Pimentel y Ugarte 2012; True 1975). Al menos desde el Arcaico Tardío (ca. 6000-4000 a.P.), ya se encontraban insertas en una red macroregional de circulación de bienes e ideas (Ballester y Gallardo 2011), pero es hacia el Formativo cuando estas relaciones se intensifican y cambian cualitativamente. Su economía excedentaria -posibilitada gracias a sus tecnologías de explotación marina y a la capacidad de conservación y almacenamiento de pescado- los posicionó de forma privilegiada dentro de las esferas de intercambio regional, logrando acceder a bienes culturales de altísimo valor y provenientes de cientos de kilómetros de distancia (Ballester y Clarot 2014; Ballester y Gallardo 2011; Núñez 1971; Pestle et al. 2015; Torres-Rouff, Pestle y Gallardo 2012).

El cementerio de El Vertedero Municipal de Antofagasta es un claro ejemplo de esta realidad social. Ubicado en la Quebrada de La Chimba en la ciudad de Antofagasta ( $23^{\circ} 33^{\prime} \mathrm{S}$ ) (Figura 1), el sitio fue descubierto mientras se construía el vertedero municipal. De las excavaciones se recuperaron los cuerpos de un infante y seis adultos, acompañados de un riquísimo ajuar de bienes locales y foráneos, entre los que se destaca la presencia de cuatro pipas de piedra en forma de $\mathrm{T}$ invertida, con claras evidencias de haber sido utilizadas. Este material arqueológico sirvió de base para el presente artículo (Tabla 1; Figura 2).

El estudio bioantropológico mostró que los individuos llevaron una vida íntimamente ligada al mar, tal como lo reflejan sus patologías dentales desgaste dental plano con oquedades asociadas a elementos abrasivos- y los valores de $\delta \mathrm{N}^{15}$ arrojados por los análisis de isótopos estables de los individuos 4 y 6 (Tabla 1). Estos últimos son comparables a los del resto de las poblaciones litorales del Formativo (Ballester y Clarot 2014; Pestle et al. 2015).

Del total de cuerpos rescatados, sólo el individuo 4 presentaba restos de cabello que permitieran llevar a cabo un análisis químico para detectar el posible consumo de sustancias. Estos se conservaron de forma diferencial gracias a que su cabeza se encontraba cubierta por un turbante, una vestimenta típica del Formativo entre la gente de Arica, Tarapacá y Atacama (Agüero 1994, 2012; Agüero y Cases 2004; Gallardo 1993).

\section{Materiales y Métodos}

\section{Análisis de los Residuos Adheridos}

Las sustancias adheridas en una pieza como resultado de su uso suelen ser resistentes al paso del tiempo y por ello importantes para conocer el empleo del artefacto. En particular, los restos del interior de una pipa son el resultado del proceso de formación del residuo arqueológico producido por la suma de múltiples eventos de calcinación, mezcla de sustancias y limpieza (Schiffer 1972, 1983), y solamente mediante una lectura adecuada pueden mostrar un promedio de su historia de vida. La búsqueda de indicadores sobre estos usos específicos se abordó desde dos tipos de análisis que, en conjunto, se enriquecen y complementan: la cromatografía de gases acoplada a espectrometría de masas y los microrrestos vegetales.

La toma de la muestra se realizó mediante el raspado directo en húmedo (Loy 1994). El residuo recuperado se obtuvo en tres fases: primero el sedimento postdepositacional, luego el lavado y finalmente el raspado directo de la superficie de la pieza y sus intersticios, donde se localizan principalmente los microfósiles (McRostie 2010). El sedimento y el raspado se obtuvieron utilizando un objeto punzante de plástico (Cueto et al. 2010). Los residuos se retiraron del tubo y hornillo por separado para establecer comparaciones con otros estudios. Todos los materiales utilizados para la toma de muestras se higienizaron previamente, siguiendo el protocolo señalado por Belmar et al. (2014).

\section{Análisis de Microrrestos Vegetales}

Los microfósiles vegetales son distintos tipos de partículas microscópicas, como granos de almidón, silicofitolitos, cristales de oxalato de calcio, granos de polen, anillos de celulosa y diatomeas (Korstanje 2010), que corresponden a órganos, estructuras o inclusiones celulares que constituyen indicadores o elementos diagnósticos de la presencia de plantas en lugares donde los procesos de descomposición de la materia orgánica no han permitido la supervivencia de macrorrestos vegetales. 


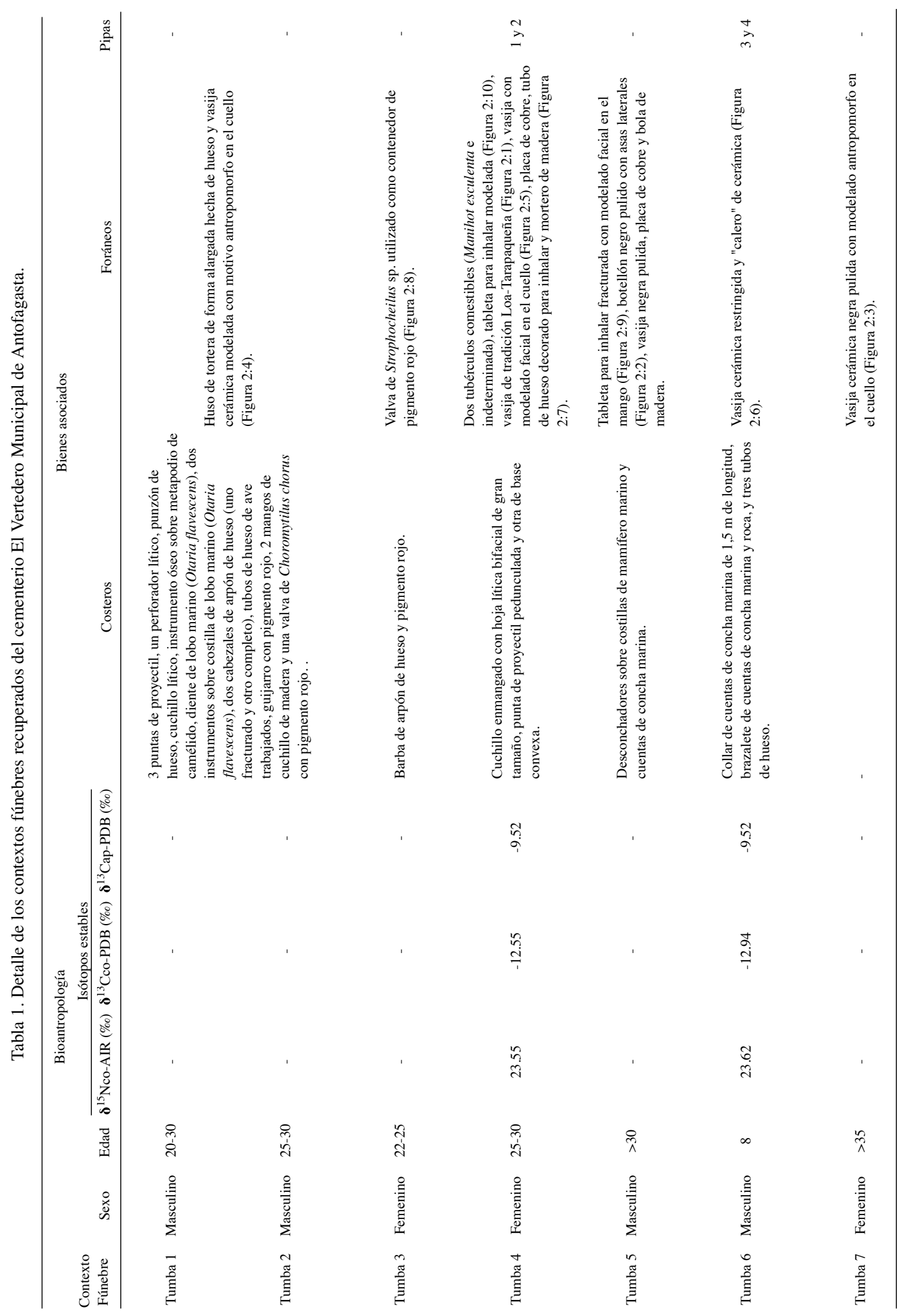




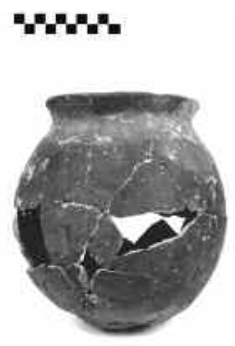

1

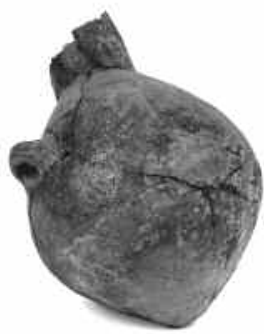

2

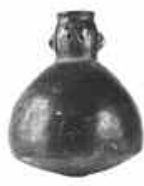

3

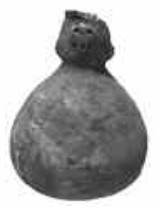

4

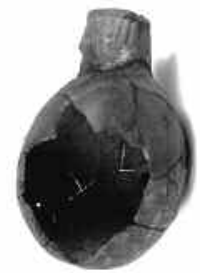

5

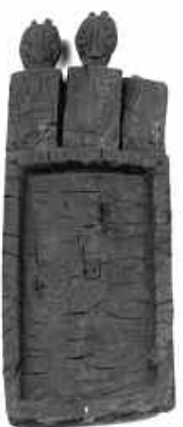

10

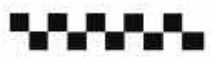

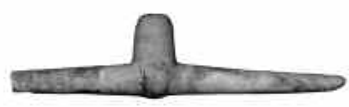

11

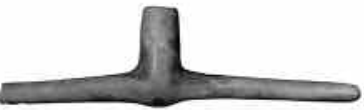

12

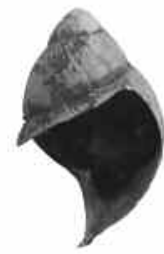

8

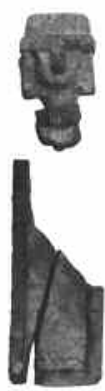

9

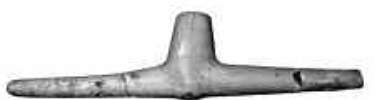

13

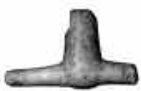

14

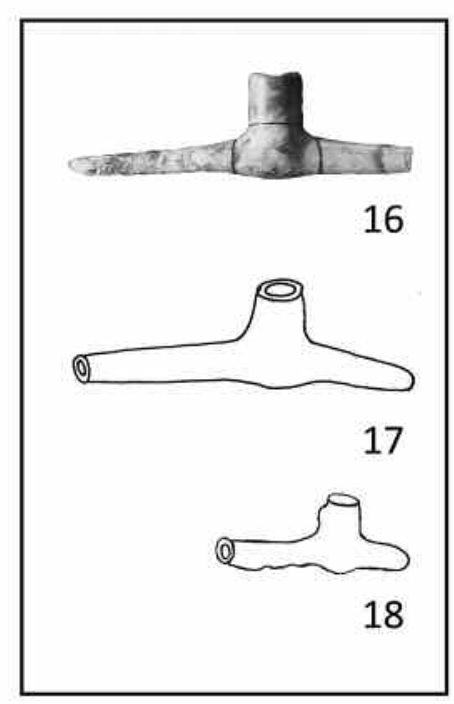

Figura 2. (1-15) Materiales arqueológicos ofrendados en el cementerio EI Vertedero Municipal de Antofagasta: (1) Vasija cerámica tipo Quillagua-Tarapacá; (2, 3 y 4) Vasijas cerámicas tipo San Pedro Negro Pulido; (5) Vasija cerámica de procedencia indeterminada; (6) "calero" de cerámica; (7) mortero de madera; (8) contenedor de pigmento sobre valva de Strophocheilus sp.; (9-10) tabletas de madera para inhalar; (11) pipa 1; (12) pipa 2; (13) pipa 3; (14) pipa 4; (15) detalle en perspectiva de la pipa 2; (16-18) Pipas en " $T$ " invertida recuperadas por Augusto Capdeville en la costa de Taltal: (16) Caleta Las Guaneras (Capdeville 1920:Figura 11); (17) Caleta Oliva (Mostny 1964:206); (18) Cementerio de los Vasos Pintados (Mostny 1964:40). 
Estos elementos poseen características particulares con valor taxonómico, además de la potencialidad de dar cuenta de daños en las partículas, relacionados con prácticas culturales, permitiendo observar modalidades de procesamiento a través de alteraciones morfológicas, principalmente cuando el vegetal se ve expuesto a altas temperaturas (Babot 2003). Es por su alta resistencia al paso del tiempo, que los microfósiles son un registro fiable de la historia del artefacto, lo que los transforma en una excelente herramienta para responder a los usos de los artefactos en arqueología.

A fin de tener una visión completa del contenido de las pipas, se tomó en consideración la propuesta de Coil et al. (2003) de un "análisis múltiple de microfósiles”. Esta posibilita observar íntegramente la información obtenida desde distintas líneas de evidencia, generando un panorama amplio de indicadores por sobre el específico que entrega un único microfósil en la determinación taxonómica.

Si bien el análisis múltiple es simple al momento de elaborar colecciones de referencia, se complejiza en el registro arqueológico por ser éste el resultado de una sucesión de eventos de uso.

Posterior al montado de los residuos, estos fueron revisados mediante microscopio petrográfico con cámara incorporada y sistema Metrometrics, en aumentos de 250x y 400x.

La descripción de la forma y tipología de los fitolitos se realizó según el código generado por Madella et al. (2005). En cuanto a los granos de almidón, se evaluó su número, forma, dimensiones, tamaño de las lamelas, hilo y cruz de extinción y sus alteraciones. Los otros microrrestos fueron sólo descritos y cuantificados.

La identificación se realizó sobre la base de colecciones de referencia y publicaciones relacionadas, relativas a plantas fumables y afines del área de estudio (Babot 2003; Belmar et al. 2015; Korstanje y Babot 2007; Pearsall y Piperno 1993; Piperno 2006; Planella et al. 2009; Quiroz et al. 2012).

\section{Preparación de Extractos para el Análisis Químico de Residuos}

Las muestras de residuos se extrajeron empleando dos solventes de polaridades diferentes, cloroformo y metanol, con el objeto de posibilitar el aislamiento y la eventual identificación de un rango amplio de alcaloides.
La extracción del residuo desde el agua de los lavados se realizó por centrifugación a $3.000 \mathrm{rpm}$ durante $30 \mathrm{~min}$, seguida de la extracción mecánica del sobrenadante y del secado del residuo en un desecador con gel de sílice durante 72 horas a temperatura ambiente. Las muestras de residuos sólidos (raspados, sedimentos y lavados) se pulverizaron y extrajeron con $500 \mu$ lde cloroformo (calidad HPLC, JTBaker, EE.UU. de N.A.) por maceración en un baño ultrasónico a intensidad media por $15 \mathrm{~min}$ a $25^{\circ} \mathrm{C}$ y posteriormente agitación vorticial a temperatura ambiente por $60 \mathrm{~min}$. La suspensión se filtró a través de un conjunto de tres filtros en serie, compuestos por una mota de algodón colocada en la punta de una pipeta Pasteur, y usando una alícuota adicional de $500 \mu 1$ de cloroformo para enjuagar los filtros. Los eluídos se colectaron en viales ámbar de $2 \mathrm{ml}$ con tapa a rosca y revestimiento interno de teflón y se evaporaron bajo una corriente de nitrógeno. Los residuos sólidos se transfirieron a microinsertos de vidrio de $100 \mu 1$, usando sucesivamente 50 y 20 $\mu \mathrm{l}$ de cloroformo seguidos de evaporación; finalmente, los extractos se reconstituyeron con $20 \mu \mathrm{l}$ de cloroformo. Este procedimiento minimizó la cantidad de extracto retenido en las paredes del vial. Por otra parte, el cloroformo se evaporó del filtro de lana de algodón y el material sólido adherido a ella fue extraído con $500 \mu 1$ de metanol (calidad HPLC, JT Baker, EE.UU. de N.A.). Para la preparación de los extractos metanólicos se siguió el mismo procedimiento al utilizado en la preparación de los clorofórmicos.

Aunque la metodología óptima para la extracción y purificación de alcaloides desde matrices complejas consiste en la utilización de extracciones ácido-base, ésta no se aplicó debido a la reducida cantidad de material (ca. $10 \mathrm{mg}$ en promedio) y a que la cantidad de alcaloides presentes en ella se suponía estaría cercana al límite de detección del método implementado (ca. 5 ng de nicotina en una inyección). Esta suposición fue corroborada: los residuos analizados contenían una media de ca. 100 ng de nicotina.

\section{Preparación de Extractos para el Análisis Químico de Cabello}

Se cortaron hebras de cabello (ca. $100 \mathrm{mg}$ ) en segmentos de $1 \mathrm{~mm}$ que se lavaron con $3 \times 3 \mathrm{ml}$ de cloroformo durante 15 min cada vez y se filtraron 
a través de un material compuesto por una capa de malla de acero con orificios de, $20 \mathrm{~mm}$ y cinco capas de malla de acero con orificios de, $25 \mathrm{~mm}$ (Millipore Corporation, Billerica, MA, EE.UU. de N.A.) utilizando una jeringa de vidrio de $5 \mathrm{ml}$ Ultrafit (Henke, Sass Wolf GmbH, Alemania). El lavado del cabello es un paso imprescindible para evitar el riesgo de falsos positivos exógenos (Dupont y Baumgartner 1995) y para excluir del análisis la nicotina a la que el individuo en estudio pudo haber estado expuesto por encontrarse en ambientes donde se fumaba (Wells 2000).

El cabello lavado fue finamente pulverizado colocándolo en microviales de acero inoxidable de $1,8 \mathrm{ml}$ con tapas de polietileno que contenían 25 bolas de acero inoxidable de $1 \mathrm{~mm}$ de diámetro, y agitándolo durante $10 \mathrm{~min}$ en un pulverizador (Mini-BeadBeater-96; Biospec Inc., Bartlesville, OK, EE.UU. de N.A.). Las muestras de cabello pulverizado se maceraron en $500 \mu$ lde cloroformo con agitación vorticial periódica a temperatura ambiente durante 72 horas y la suspensión se filtró mediante lana de algodón colocada en la punta de una pipeta Pasteur utilizando una alícuota de 500 $\mu 1$ de cloroformo adicional. El cabello restante se secó bajo flujo de nitrógeno y se maceró en $1 \mathrm{ml}$ de metanol con agitación vorticial periódica a temperatura ambiente durante 72 horas. Los extractos metanólicos se filtraron a través de lana de algodón colocada en la punta de una pipeta Pasteur usando una alícuota adicional de $1 \mathrm{ml}$ de metanol. Todos los extractos se recogieron primero en viales de color ámbar de $2 \mathrm{ml}$ con tapones de rosca con revestimiento de teflón. Las alícuotas de ellos se transfirieron repetidamente a un inserto de vidrio de $100 \mu 1$ en un vial de color ámbar, en el que fueron llevadas a sequedad por medio de un flujo de nitrógeno. Para los análisis de cromatografía de gases acoplada a espectrometría de masas (CG/EM) los extractos se reconstituyeron en $15 \mu \mathrm{l}$ del solvente respectivo.

\section{Análisis Cromatográfico de los Extractos}

El análisis por cromatografía de gases acoplada a espectrometría de masas (CG-EM) se realizó en un cromatógrafo de gases Shimadzu (GCMS-QP Ultra 2010, Kyoto, Japón) con un inyector funcionando en el modo sin división de la muestra y equipado con una columna capilar modelo Rtx5MS Crossbond 5 por ciento difenil-95 por ciento dimetilpolisiloxano (Restek, Bellefonte, PA, EE.UU. de N.A.) de $30 \mathrm{~m}$ de longitud, ,25 $\mathrm{mm}$ de diámetro interior y $25 \mu \mathrm{m}$ de espesor de la película. La temperatura de la columna se mantuvo a $30^{\circ} \mathrm{C}$ durante $3 \mathrm{~min}$, y se elevó en $25^{\circ} \mathrm{C} / \mathrm{min}$ hasta $230^{\circ} \mathrm{C}$, manteniéndose a esta temperatura durante $10 \mathrm{~min}$. El volumen de inyección fue de $2 \mu 1 \mathrm{y}$ el gas portador helio (flujo: $1,3 \mathrm{ml} / \mathrm{min}$ ). El espectrómetro de masas fue usado en el modo de ionización por impacto electrónico $(70 \mathrm{eV})$ con una corriente de emisión de $250 \mu \mathrm{A}$. Las temperaturas del puerto de inyección, la fuente de iones y la línea de transferencia fueron de $250^{\circ} \mathrm{C}, 250^{\circ} \mathrm{C}$ y $280^{\circ} \mathrm{C}$, respectivamente. El instrumento fue operado en los modos de barrido completo de iones (BCI) y de monitorización selectiva de iones (MSI). Se incluyeron en el análisis MSI los principales iones de alcaloides encontrados en pipas de Chile y Argentina: nicotina (m/z 84 y 133) (Echeverría et al 2014), dimetiltriptaminas $(N, N$ dimetiltriptamina: $m / z, 58$ y $130 ; 5$-metoxi- $N, N-$ dimetiltriptamina: $\mathrm{m} / z$, 58 y 218 ; 5-hidroxi- $N, N$ dimetiltriptamina: $m / z 58$ y 146) (Bugliani et al. 2010; Rosso y Spano 2005-2006) y cocaína $(\mathrm{m} / \mathrm{z}$ 82 y 182) (Andreoni et al. 2012; Capparelli et al. 2006).

Se consideró una identificación positiva de la nicotina cuando el cromatograma de la muestra mostró un pico dentro del rango de tiempo de retención de la nicotina pura (media $=9,78 \mathrm{~min}$; rango $=9,65-9,91 \mathrm{~min}$ ) y la relación entre los iones con $m / z 84$ y 133 cayó dentro de una desviación estándar de la media de las muestras de la nicotina pura (media $=3,66$; rango $=3,04-4,60$ ).

\section{Resultados}

\section{Análisis de Microrrestos Vegetales}

Las muestras revisadas bajo el microscopio petrográfico se observaron en su totalidad siguiendo transectas. Se registraron 72 microrrestos, de los cuales 41 fueron hallados en tubo y 31 en hornillo; los microrrestos fueron clasificados en 18 morfotipos (Tabla 2, Figura 3).

En las muestras de raspado directo del hornillo de la pipa 2 se identificó Nicotiana sp. a partir de tres granos de almidón cuyos rasgos diagnósticos fueron el morfotipo esférico con cruz de extinción céntrica y lamelas triangulares (Tabla 2) (Quiroz 


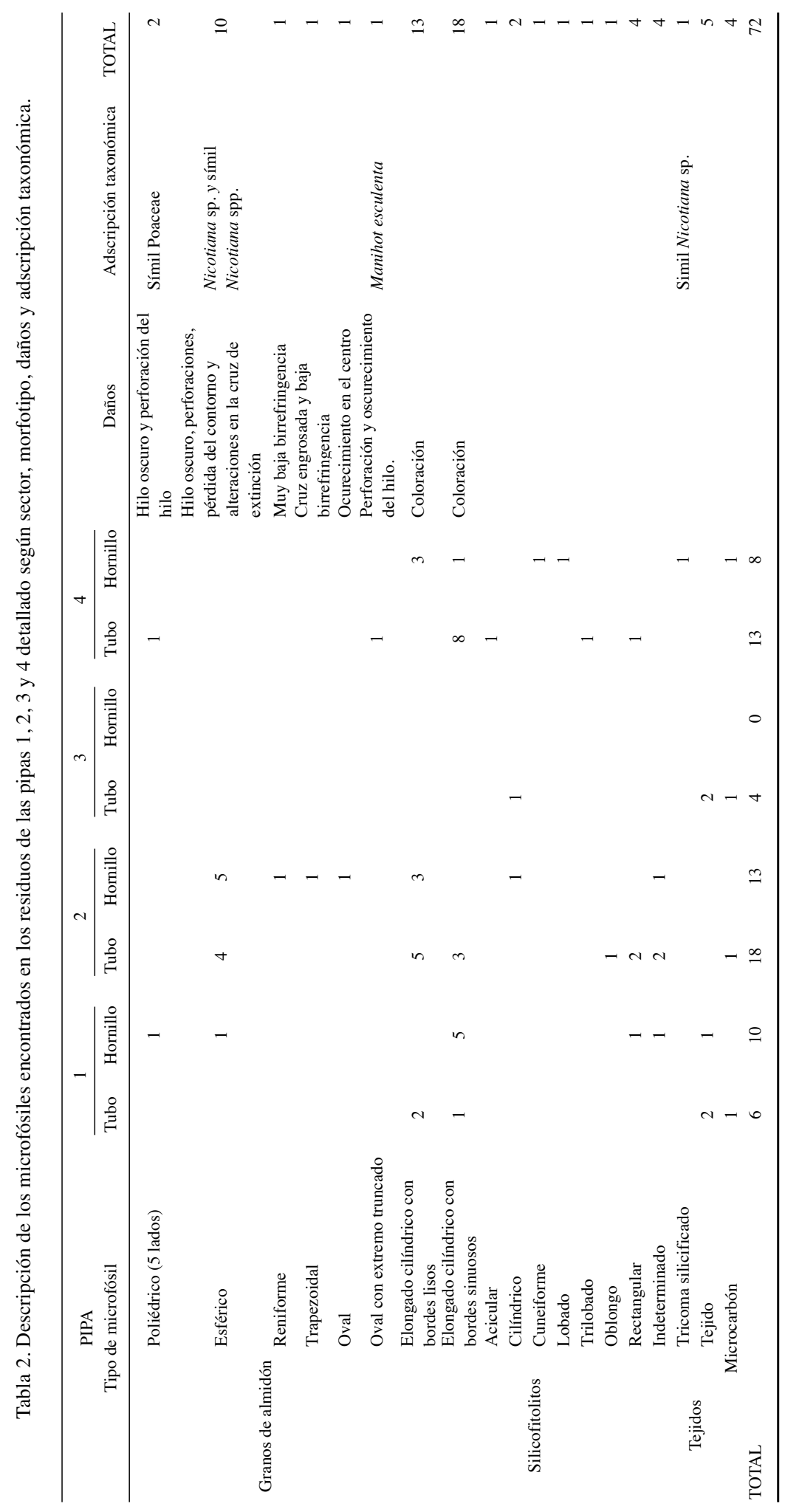




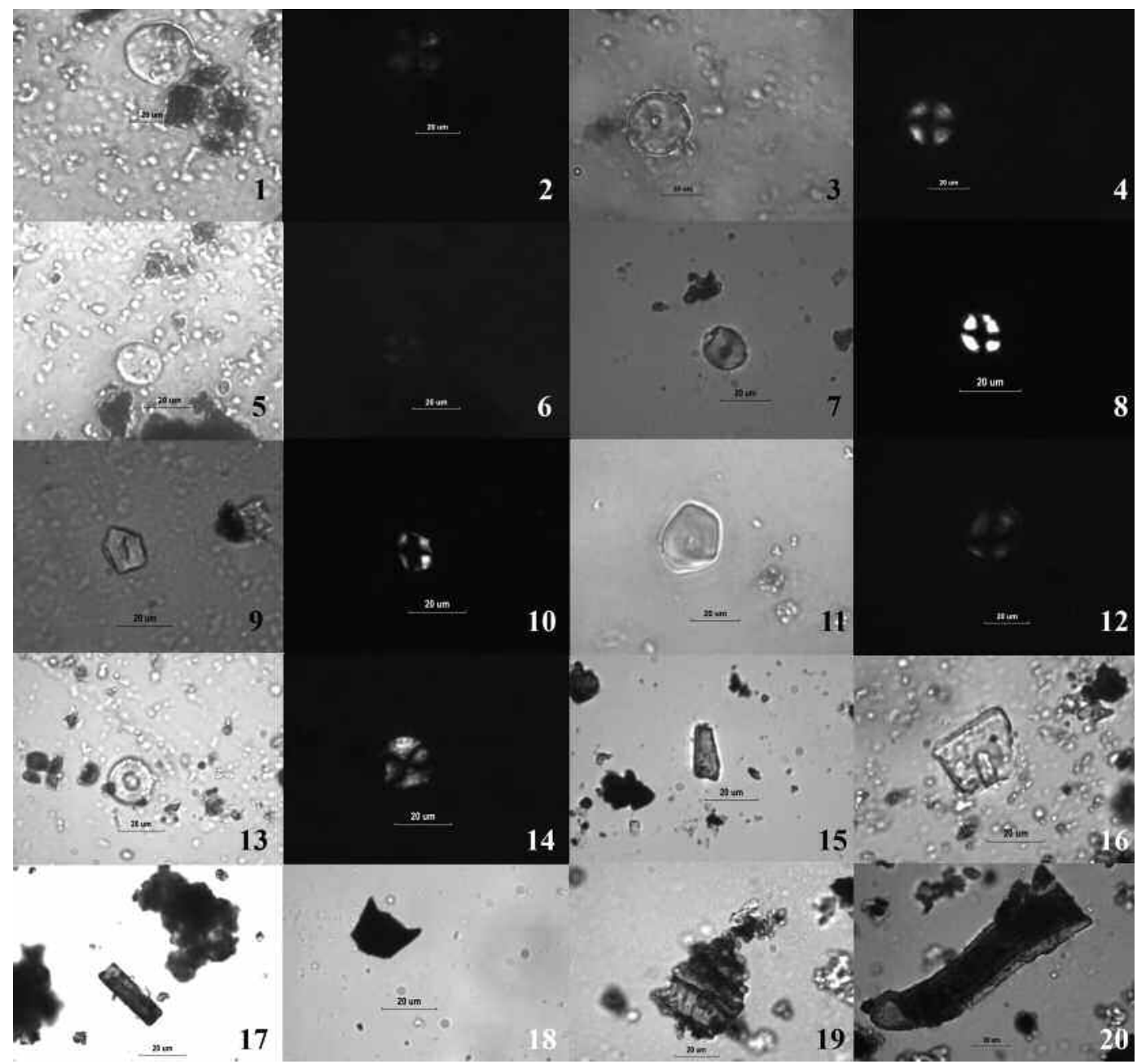

Figura 3. Microrrestos obtenidos del interior de las pipas estudiadas: (1-6) imágenes de granos de almidón atribuibles a Nicotiana sp. Izquierda con luz reflejada y derecha con luz polarizada. Presentan daños en el hilo y birrefringencia; (7 y 8$)$ grano de almidón símil Manihot esculenta con daños en el hilo, (7) en campo claro y (8) con luz polarizada; (9 y 10) grano de almidón símil Poaceae. con daños en el hilo (Piperno 2006), (9) en campo claro y (10) luz polarizada; (11 y 12) imágenes en campo claro y polarizada de grano de almidón de cinco lados, con hilo excéntrico y engrosado, dañado en birrefringencia; (13 y 14) imágenes en campo claro y polarizada de grano de almidón esférico con hilo concéntrico; (15) fitolito acicular; (16) fitolito trapezoidal; (17) célula larga con alteración en coloración; (18) microcarbón; (19 y 20) tejido con alteración en coloración.

et al. 2012). Asociado a este conjunto se registró un grano de almidón esférico, otro trapezoidal y fitolitos del tipo elongado cilíndrico de bordes lisos y sinuosos (Figura 3:9-10), asociados a la presencia de poáceas (Piperno 2006). En el tubo se identificó Nicotiana sp. a partir de dos granos de almidón; también se recuperaron fitolitos de tipo rectangular y oblongo (Tabla 2). Todos los granos de almidón presentaron, tanto en tubo como en hornillo, daños asociados al hilo (oscu- recimiento), la cruz (ensanchamiento) y una baja birrefringencia (Figura 3:1-6) (Babot 2009).

La pipa 4 registró en su tubo la presencia de un grano de almidón esférico de extremo truncado de Manihot esculenta (Figura 3:7-8) (Piperno y Holst 1998) y un grano de almidón poliédrico de cinco lados, asociado a células largas asignables a poáceas (Figura 3:9), mientras que en su hornillo registró un tricoma silicificado similar a Nicotiana sp. (Tabla 2). 
Las pipas 1 y 3 presentaron un conjunto de microfósiles sin asignación taxonómica. En la pipa 1 se registraron 16 microrrestos como tejidos, microcarbones, fitolitos elongados cilíndricos de bordes lisos y sinuosos, y granos de almidón de tipo esférico y poliédrico de cinco lados (Tabla 2). La pipa 3 arrojó una baja diversidad de morfotipos de microfósiles -un microcarbón, tejidos y un fitolito cilíndrico- cuyas características al menos permiten señalar que la pipa fue utilizada para fumar (Tabla 2).

El conjunto de microrrestos de las cuatro pipas presentó daños y alteraciones en la coloración, en el caso de los fitolitos, y de birrefringencia e hilo en los granos de almidón (Tabla 2). Estos últimos se encontraron mayoritariamente agrietados y fisurados, con perforaciones, lo que provocó que perdieran brillo y visibilidad. Estas alteraciones observadas en los granos de almidón y en la coloración del resto del conjunto resultaron coherentes con lo documentado por Babot $(2003,2009)$ para procesamientos mediante calor, calcinamiento y molienda.

\section{Análisis Químico de los Residuos}

Los extractos clorofórmicos de los residuos no indicaron la presencia de ninguno de los alcaloides buscados. Los extractos metanólicos mostraron la existencia de nicotina en el sedimento y lavado del tubo, y en el sedimento, lavado y raspado del hornillo de la pipa 2 (Figura 4); además, se encontró nicotina en el sedimento del hornillo de la pipa 4. No se registró nicotina en ninguna de las fases o partes de las pipas 1 y 3 . Los análisis mostraron la ausencia de triptaminas y cocaína en todas las fases y partes de las cuatro pipas.

En los extractos clorofórmicos se encontró trans-escualeno, ftalatos e hidrocarburos de cadena lineal y ramificados con $\mathrm{C} 16$ a C30, mientras que en los extractos metanólicos se encontraron metil ésteres de ácidos grasos, destacándose los derivados de los ácidos palmítico y esteárico.

\section{Análisis Químico de Cabello}

Los extractos clorofórmicos correspondientes al lavado preventivo y al extracto del cabello mostraron la ausencia de los alcaloides evaluados. El análisis químico del extracto metanólico en la modalidad MSI para alcaloides específicos sólo mostró la presencia de nicotina basada en el tiempo de retención y en la intensidad de los iones analizados. Los otros alcaloides monitoreados no fueron identificados en los extractos.

\section{Discusión y Conclusiones}

Los métodos arqueobotánico y químico no siempre conducen individualmente a una identificación satisfactoria, debido a variables como el nivel de daño y preservación de los microrrestos, la ausencia de colecciones de referencia adecuadas, la transformación de los compuestos químicos y el límite de detección del análisis químico. Por otra parte, el análisis de residuos está también limitado por procesos de lixiviación que pueden transportar los marcadores arqueobotánicos o químicos fuera de su lugar de origen y por contaminación que el objeto pueda haber sufrido, por lo que es importante extraer y comparar el sedimento depositacional con el residuo cultural. Sin embargo, la aplicación conjunta de ambos métodos genera información complementaria, transformándola en una herramienta analítica robusta para el análisis de residuos adheridos.

Ambos métodos permitieron dar cuenta tanto del empleo de los artefactos como de las sustancias consumidas. Es así como la presencia de microcarbones en todas las pipas y la constatación de daños asociados con la exposición al fuego o incluso calcinamiento en los granos de almidón y en los fitolitos evidenciaron que todas las pipas fueron utilizadas para fumar. Con respecto a las sustancias fumadas, ambos métodos produjeron resultados coincidentes: presencia de nicotina y microrrestos de Nicotiana en residuos de las pipas 2 y 4 y ausencia en las pipas 1 y 3 . Es interesante notar que los microfósiles de Nicotiana presentes en la pipa 2 se encontraron sólo en los raspados de hornillo y tubo, mientras que químicamente la nicotina se detectó en el raspado, lavado y sedimento del hornillo y en el lavado y sedimento del tubo (Tabla 2). La ausencia de nicotina en el raspado del tubo de esta pipa puede atribuirse a la lixiviación del alcaloide desde la pipa al medio externo y su retención en la matriz circundante, en tanto que la ausencia de microfósiles en el lavado y sedimento de tubo y hornillo de la pipa 2 puede obedecer a que la superficie del artefacto constituye un mecanismo de protección y retención de los microrrestos (Haslam 2004) o a que la técnica 

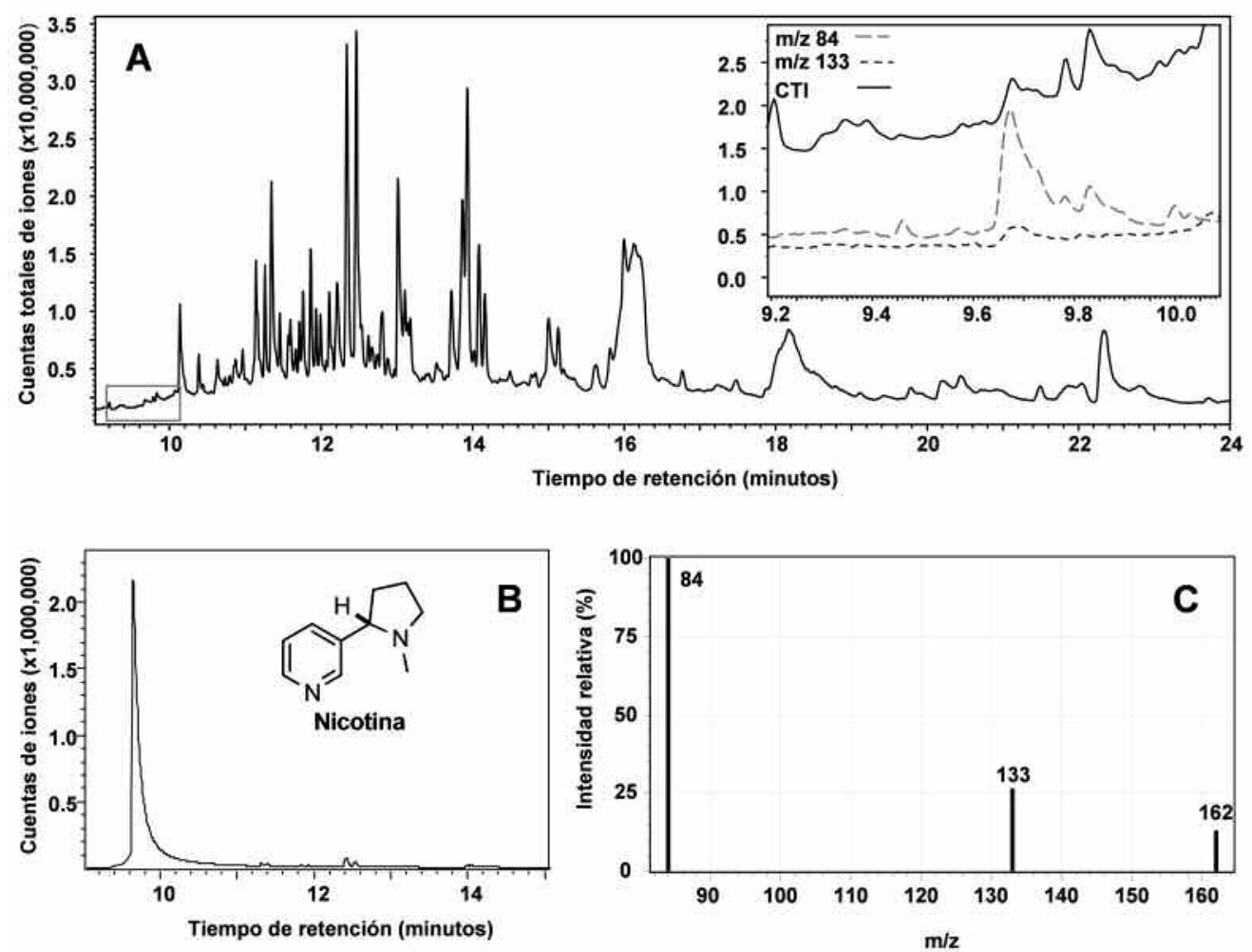

Figura 4. Análisis por cromatografía de gases acoplada a espectrometría de masas del extracto obtenido a partir del lavado de la pipa 2: (a) Cromatograma en el modo de barrido completo de la muestra; en el inserto se muestra el cromatograma en el modo de monitorización selectiva de los iones con $\mathrm{m} / \mathrm{z} 84$ y 133, mayoritarios en el espectro de masas de la nicotina, en la zona de aparición de la nicotina (se muestra también una curva correspondiente a la suma total de iones); (b) cromatograma en el modo de barrido completo de la nicotina; (c) espectro de masas de la nicotina.

de la alícuota sólo examina parte de la muestra: si los microfósiles son escasos y la probabilidad de encontrarlos en el conjunto del residuo es baja, su probabilidad de aparición en una alícuota es aún menor. No se registraron microfósiles en ningún lavado, sin duda debido a la dilución en que se encuentra el residuo en esta fase. Como conjunto, estos resultados muestran la utilidad de someter a análisis tanto los sedimentos como los residuos propiamente tales.

La presencia de trans-escualeno es considerada consecuencia de la manipulación humana de los artefactos y los ftalatos e hidrocarburos de alto peso molecular, de su almacenamiento en contenedores de plástico (Evershed 1993). Por otra parte, aunque se ha relacionado el cociente entre las concentraciones de ácidos esteárico y palmítico con el origen del material graso (Copley et al. 2005), estudios posteriores han demostrado la baja confiabilidad de la asignación (Koirala y Rosen- treter 2009). En consecuencia, no se cuantificaron esos compuestos en los cromatogramas; sin embargo, una inspección cualititativa no mostró diferencias claras entre las distintas pipas analizadas. Es interesante destacar que estos compuestos han sido observados previamente en residuos de pipas del Noroeste Argentino (Pazzarelli 2011).

La aparición de restos de Nicotiana o señales de nicotina ha sido previamente registrada en pipas en otras localidades, extendiendo geográficamente la costumbre del consumo de esta sustancia a lugares como el Noroeste Argentino y el Centro-Sur de Chile (Andreoni et al. 2012; Capparelli et al. 2006; Echeverría et al. 2014; Quiroz et al. 2012). En San Pedro de Atacama (distante a 230 km), análisis químicos de cabello humano de individuos de distintos momentos de su prehistoria (100 a.C.1450 cal d.C.) mostraron consumo de nicotina por una alta proporción de individuos (Echeverría y Niemeyer 2013). Si bien en este último caso no se 
pudo distinguir cómo se realizó su consumo, sea masticado, fumado o inhalado, quedó en evidencia su importancia para las poblaciones locales. $\mathrm{Su}$ aprovisionamiento pudo realizarse a través del intercambio o mediante el abastecimiento directo; esta última alternativa seguramente la más recurrente, dada la existencia de especies de Nicotiana en la región, registrándose colectas en las quebradas que desembocan al Salar de Atacama (Socaire y Talabre), en los salares altoandinos (Pajonales, Aguas Calientes) y lagunas altiplánicas (Miscanti y Tuyaito) (Figura 1).

En nuestra área de estudio, a lo largo de la franja costera humedecida por la camanchaca entre Antofagasta y Chañaral, crece $N$. solanifolia como única especie nativa de Nicotiana (Dillon 2005; Goodspeed 1954; Johnston 1929; Marticorena et al. 1998; Ricardi 1957; Rundel et al. 1991). Su presencia local la convirtió en un recurso accesible dentro de los circuitos de movilidad de los grupos cazadores-recolectores marinos en una lógica de abastecimiento inserto (Embedded procurement) (Binford 1979). Estas comunidades, si bien habitaban en residencias estables, disponían de una estrategia de movilidad logística a lo largo del litoral, la cordillera de la costa y la pampa, desplazándose desde su caleta más de $250 \mathrm{~km}$ por la costa y $80 \mathrm{~km}$ hacia el interior del desierto (Ballester y Gallardo 2011; Blanco 2013; Blanco et al. 2010; Cases et al. 2008; Knudson et al. 2012; Pimentel 2012; Pimentel et al. 2011; Torres-Rouff, Pimentel y Ugarte 2012). En efecto, algunas de las localidades en que fue colectada $N$. solanifolia se encuentran cercanas a los cementerios Formativos desde donde Augusto Capdeville recuperó las pipas de piedra en forma de $\mathrm{T}$ invertida mencionadas al comienzo (Figura 1) (Ballester y Clarot 2014; Capdeville 1928; Mostny 1964). La posibilidad de abastecimiento directo no significa que ésta fuera la única vía de obtención del recurso vegetal, ya que al ser Nicotiana un género de amplia distribución regional y presente en diversas localidades del Desierto de Atacama (Figura 1), pudo también circular entre comunidades a través de relaciones de intercambio, aunque hasta el momento no existe evidencia arqueológica en contextos vinculados al tráfico de bienes como rutas y vías de circulación (Pimentel 2012).

El hallazgo de nicotina en el cabello del individuo 4 es una prueba directa de su consumo por parte de las poblaciones litorales de Antofagasta, lo que asociado a las evidencias en individuos de San Pedro de Atacama (Echeverría y Niemeyer 2013), la convierten en una práctica bastante regular y extendida a lo largo y ancho del Desierto de Atacama.

Pero la práctica fumatoria no se centró únicamente en torno a la Nicotiana. Dos de las pipas analizadas -una de cada par ofrendado- arrojaron negativo a su presencia y a las principales sustancias psicoactivas conocidas para la región, aun siendo que mostraban claras evidencias de haber sido utilizadas para fumar. Aunque estos resultados negativos pueden ser consecuencia de factores como sensibilidad del método analítico y/o la pérdida del material químico por lixiviación o transformación química, bien podrían también ser consecuencia del uso de las pipas para el consumo de sustancias que no sólo involucraban la búsqueda alteraciones biológicas, dándole un mayor valor a la práctica del fumar que a los efectos mentales y sensoriales de ciertas sustancias.

A escala macroregional también se ha registrado un consumo diversificado de especies vegetales al fumar, identificando en general dos categorías de plantas: aquellas que presentan alcaloides, como el tabaco (Nicotiana sp.), coca (Erythroxylum coca), yerba mate (Ilex sp.) y cebil (Anadenanthera sp.) (Bugliani et al. 2010; Fernández Distel 1980; Gili y Villagrán 2011; Rosso y Spano 2005-2006), y las que no, como cedrón (Aloysia citriodora), maíces (Zea mays) y algodón (aff. Gossypium sp.) (Andreoni et al. 2012; Capparelli et al. 2006). Seguramente la presencia de ambos conjuntos responde a usos y fines distintos de los recursos vegetales; en el primer caso por sus propiedades analgésicas, de alteración mental y de consciencia (Elferink 1983; Janiger y Dobkin 1973, 1976; Wilbert 1991), mientras que en el segundo, por sus cualidades aromáticas, gustativas o como parte de prácticas paralelas pero necesarias al mismo fumar, como limpieza y/o encendido de las pipas, entre otras posibles razones.

La presencia de pipas en el litoral desértico se restringe únicamente desde Antofagasta hacia el sur, mientras que hacia el norte si bien la cantidad de excavaciones sistemáticas ha sido muchísimo mayor y con mejor control arqueológico (Ballester y Clarot 2014; Núñez 1971; Spahni 1967), hasta el momento no se han registrado pipas, a excep- 
ción de una manufacturada en cerámica ofrendada a un entierro en la ruta de Calate, entre Caleta Huelén-Quillagua, a $25 \mathrm{~km}$ de la costa (TorresRouff, Pimentel y Ugarte 2012). A juzgar por el bajo número de pipas conocidas para el Formativo del litoral (Mostny 1964), la escala de la práctica fumatoria y la popularidad de la costumbre entre estas poblaciones debieron ser más bien reducidas y eventuales. En esto sólo se podrá profundizar cuando se excaven y estudien de forma sistemática mayor cantidad de contextos de este tipo.

La tradición de uso de pipas de piedra en $\mathrm{T}$ invertida tiene su zona de mayor popularidad y distribución geográfica hacia el sur del área de estudio, entre los valles Copiapó $\left(27^{\circ} 40^{\prime} \mathrm{S}\right)$ y Elqui (30³0'S), dentro de lo que se ha definido como el Complejo El Molle (ca. 2000-1200 a.P.) (Cornely 1940, 1951, 1956; Latcham 1940; Niemeyer et al. 1989; Westfall 1993-1994). Su presencia en el litoral de Antofagasta debió ser consecuencia de actividades de intercambio u otras formas de circulación de bienes -como regalos y dones- entre grupos litorales para afianzar vínculos políticos en instancias de congregación social -matrimonios, ritos fúnebres, etc.- o en alguno de sus tantos encuentros esporádicos durante las faenas de pesca, situaciones en que podían viajar cientos de kilómetros fuera de su bahía de residencia (Ballester y Clarot 2014; Ballester y Gallardo 2011; Ballester et al. 2010; Bittmann 1986; Casassas 1974; Larraín 1974, 1978; True 1975). La movilidad longitudinal sobre el eje litoral y los estrechos vínculos sociales entre los grupos costeros hicieron que junto a los pescadores viajaran bienes exóticos, expandiendo regionalmente sus esferas de distribución hacia el norte del territorio (Ballester y Gallardo 2011; Latcham 1909).

Siempre es una posibilidad que las pipas circularan ya utilizadas entre las comunidades. Pero en este caso la existencia de almidones de yuca (Manihot esculenta) con daño por calcinación en el interior del tubo de la pipa 4 y las señales de nicotina en el cabello del individuo 4, son el mejor argumento en favor de su uso local. En el primer caso, porque en otra de las tumbas fue recuperado un tubérculo de esta misma especie, y si bien ésta no crece localmente y hasta la actualidad no existe evidencia de que estos grupos cultivaran vegetales durante el Formativo, la concurrencia del tubérculo y sus granos de almidón calcinados dentro de la pipa hacen pensar en que estos mismos grupos pudieron introducir una sección de la planta ya sea para fumarla, o como parte de la limpieza y/o encendido de la pipa. El segundo caso es más elocuente, ya que el análisis químico del pelo de la mujer mostró que en vida consumió sustancias ricas en nicotina, corroborando los resultados obtenidos desde las pipas.

Resulta interesante que las pipas hayan sido ofrendadas a una mujer adulta y a un infante, una representación fúnebre que asocia la práctica fumatoria a diversos agentes sociales: niños y adultos, hombres y mujeres. Al menos desde lo acotado de este contexto la práctica fumatoria podría no estar vinculada únicamente a una parcialidad restringida, a ciertos roles o especialistas dentro de la comunidad, sino más bien a distintas clases de individuos. Este panorama es consecuente con el tipo de sociedad de estos grupos litorales: cazadores, pescadores y recolectores marinos organizados según relaciones igualitarias (Ballester y Clarot 2014; Ballester y Gallardo 2011; Ballester et al. 2010).

Un recorrido a través de las localidades del Desierto de Atacama a ambos lados de la cordillera de los Andes muestra un sinfín de matices y peculiaridades que las diferencian culturalmente. Para el Formativo las costumbres fumatorias se popularizaron mediante la aparición de distintos tipos de pipas, sobre soportes de piedra, cerámica y hueso, reflejando diferentes soluciones tecnológicas, materiales, estilísticas y estéticas en cada localidad para una misma práctica social (Berenguer et al. 1986; Capdeville 1928; Dougherty 1972; Gili 2014; Gili y Villagrán 2011; Le Paige 1964, 1974; Mostny 1964; Núñez et al. 2005, 2006; Orellana 1963, 1991; Sinclaire 2004; Tarragó 1989; Thomas et al. 1989-1990, 1995; Torres 1996, 1998; Torres et al. 1991; Torres-Rouff, Pimentel y Ugarte 2012; Westfall 1993-1994). Los matices culturales regionales son evidentes a primera vista, con pipas tubulares de hueso y piedra en el Noroeste Argentino, pipas cerámicas modeladas de hornillo grande en San Pedro de Atacama y el Noroeste Argentino, pipas líticas y cerámicas tubulares en el Loa Medio y pipas de piedra en forma de T invertida en el litoral al sur de Antofagasta.

Tal como existen diferencias regionales en cuanto al tipo de pipas, sus tamaños, formas y es- 
tilos, fueron distintas las sustancias consumidas según su grado de disponibilidad local y su posición en las redes de circulación de productos, evidenciando situaciones, contextos y seguramente experiencias diversas entre las distintas comunidades que habitaron en el Desierto de Atacama durante el Formativo. Esta situación no parece extraña si se entiende al Formativo como la instancia en que se consolidan los procesos de complejización social, donde si bien en todo el desierto se hacen comunes ciertos rasgos culturales, imaginarios y tecnologías, cada localidad lo plasma en su modo de vida de acuerdo a su particular realidad social, según sus condiciones de vida y propia historia.

Entre los pescadores, cazadores y recolectores marinos del litoral el fumar fue una práctica no especializada, donde se consumieron sustancias accesibles en su propio medio ambiente. Algunas de ellas fueron seleccionadas especialmente por sus cualidades farmacológicas y por los valores que poseían dentro de su contexto sociocultural de uso. Compartían esta costumbre con las poblaciones litorales de más al sur, de quienes obtenían las pipas además de muchos otros bienes que circulaban entre grupos altamente móviles y económicamente activos. Resulta sugerente que si bien entablaron estrechos lazos de intercambio con los grupos del interior-como muestran sus ajuares fúnebres-(Tabla 1, Figura 2), cuidaron de restringir la costumbre del fumar únicamente utilizando pipas semejantes a las de sus vecinos litorales, aun cuando desde el interior podrían haber obtenido otro tipo de pipas (Gili 2014). El circuito de circulación de las pipas tenía por tanto una línea definida socioculturalmente donde no cualquier artefacto servía, sino sólo aquel de valor reconocido dentro de la práctica común y compartida entre los grupos litorales. Estos elementos dieron unidad e identidad a una costumbre que se convirtió en una tradición entre quienes vivían en la costa desde Antofagasta hacia el sur, distinguiéndolos así de sus vecinos del interior.

Agradecimientos. Proyectos FONDECYT N¹121097, $\mathrm{N}^{\circ} 1110702$ y FONDECYT Postdoctoral N³130327. Agradecemos al Museo de Antofagasta y a los herbarios del Museo Nacional de Historia Natural (Srs. Claudio Gómez y Víctor Ardiles) y Universidad de Concepción (Sra. Alicia Marticorena) por acceso a sus colecciones y bases de datos, y al Sr. Roberto Izaurieta por su ayuda en la confección del mapa de la Figura 1.

\section{Referencias Citadas}

Agüero, Carolina

1994 Clasificación de turbantes del período Formativo Temprano en el Norte de Chile. Boletín del Comité Nacional de Conservación Textil 2:61-70.

2012 Textiles del asentamiento caserones y su cementerio: Significado social y político para la población tarapaqueña durante el período Formativo (Norte de Chile). Revista de Antropología 26:59-94.

Agüero, Carolina, y Bárbara Cases

2004 Quillagua y los textiles Formativos del Norte Grande de Chile. Chungará, Revista de Antropología Chilena, Volumen Especial:599-617.

Agüero, Carolina, Patricia Ayala, Mauricio Uribe, Carlos Carrasco y Bárbara Cases

2006 El período Formativo en Quillagua, Loa Inferior (Norte de Chile). En Esferas de interacción prehistóricas y fronteras nacionales modernas: los Andes Sur Centrales, editado por Heather Lechtman, pp. 73-125. IEP, Lima.

Andreoni, Diego, Romina Spano y Verónica Lema

2012 Nota sobre evidencias de uso de plantas en el sitio Soria 2 a partir del análisis microscópico del contenido de pipas. Arqueología 18:235-243.

Ayala, Patricia

2001 Las sociedades formativas del Altiplano Circumtiticaca y Meridional y su relación con el Norte Grande de Chile. Estudios Atacameños 21:7-39.

Babot, Pilar

2003 Starch Grain Damage as an Indicator of Food Processing. En Phytolith and Starch Research in the Australian-Pacific-Asian Regions: The State of the Art, editado por Diane Hart y Linley Wallis, pp. 69-81. Pandamus Books for the Centre for Archaeological Research, Canberra.

2009 La Cocina, el taller y el ritual: Explorando las trayectorias del procesamiento vegetal en el noroeste argentino. Darwiniana 47:7-30.

Ballester, Benjamín, y Alejandro Clarot

2014 La gente de los túmulos de tierra. Marmot Impresores, Santiago.

Ballester, Benjamín, y Francisco Gallardo

2011 Prehistoric and Historic Networks on the Atacama Desert Coast (Northern Chile). Antiquity 85:875-889.

Ballester, Benjamín, Alexander San Francisco y Francisco Gallardo

2010 Modo de vida y economía doméstica de las comunidades cazadoras recolectoras costeras del Desierto de Atacama en tiempos coloniales y republicanos. Taltalia 3:21-32.

Belmar, Carolina, Luciana Quiroz, Hermann M. Niemeyer, María Teresa Planella, Ximena Albornoz, Fernanda Meneses, Silvia Alfaro, Carolina Carrasco, Katherine CollaoAlvarado y Javier Echeverría

2014 Condiciones para el uso de marcadores arqueobotánicos y químicos en estudios arqueológicos y arqueométricos sobre complejos fumatorios. Intersecciones en Antropología, en Prensa.

Belmar, Carolina, Ximena Albornoz, Silvia Alfaro, Fernanda Meneses, Carolina Carrasco, Luciana Quiroz, Pilar Babot y María Teresa Planella

2015 Reconstruyendo las prácticas fumatorias del sitio La Granja (130 a 1000 d.C., Valle del río Cachapoal, VI región, Chile Central). Chungará, Revista de Antropología Chilena, en prensa.

Berenguer, José, Ángel Deza, Álvaro Román y Agustín Llagostera

1986 La secuencia de Myriam Tarragó para San Pedro de 
Atacama: un test por termoluminiscencia. Revista Chilena de Antropología 5:17-54.

Binford, Lewis

1979 Organization and Formation Processes: Looking at Curated Technologies. Journal of Anthropological Research 35:255-273.

Bittmann, Bente

1986 Los pescadores, cazadores y recolectores de la costa árida chilena: Un modelo arqueológico. Chungará, Revista de Antropología Chilena 16-17:59-65.

Blanco, José

2013 La extracción prehispánica de recursos minerales en el internodo Quillagua-costa, Desierto de Atacama. Memoria inédita para optar al título de Arqueólogo, Universidad de Chile.

Blanco, José, Magdalena de la Maza y Charles Rees

2010 Cazadores recolectores costeros y el aprovisionamiento de recursos líticos. Perspectivas interpretativas de los eventos de talla del desierto absoluto. Werkén 13:45-68.

Bugliani, Fabiana, Marilin Calo y María Scattolin

2010 Fumando en la cocina. Determinación de contenidos por técnicas fisicoquímicas en dos pipas cerámicas del sitio Cardonal. En La arqueometría en Argentina y Latinoamérica, editado por Silvana Bertolino, Roxana Cattaneo y Andrés Izeta, pp. 231-236. Córdoba.

Capparelli, Aylen, María Leila Pochettino, Diego Andreoni y Rubén Iturriza

2006 Differences between Written and Archaeological Record: The Case of Plant Micro Remains Recovered at a Northwestern Argentinean Pipe. En Proceedings of the IVth International Congress of Ethnobotany, pp. 397406. Estambul.

Capdeville, Augusto

1920 Industria de los pueblos prehistóricos de Chile. Álbum Fotográfico. Société Scientifique du Chili, Santiago. 1928 Cómo descubrí la industria paleolítica americana de los sílices negros tallados, en zona de la costa de Taltal. Revista Chilena de Historia Natural 32:348-364.

Cartajena, Isabel

1994 Determinación de restos óseos de camélidos en dos yacimientos del Loa Medio (II Región). Estudios Atacameños 11:25-52.

Cartajena, Isabel, Lautaro Núñez y Martín Grosjean

2007 Camelid Domestication on the Western Slope of the Puna de Atacama, Northern Chile. Anthropozoologica 42:155-173.

Cases, Bárbara, Charles Rees, Gonzalo Pimentel, Rafael Labarca y Daniela Leiva

2008 Sugerencias desde un contexto funerario en un "espacio vacío" del desierto de Atacama. Boletín del Museo Chileno de Arte Precolombino 13:51-70.

Casassas, José

1974 La Región Atacameña en el siglo XVII. Datos históricos socioeconómicos sobre una comarca de América meridional. Universidad del Norte, Antofagasta.

Coil, James, Alejandra Korstanje, Steven Archer y Christine Hastorf

2003 Laboratory Goals and Considerations for Multiple Microfossil Extraction in Archaeology. Journal of Archaeological Science 30:991-1008.

Copley, Mark, Helen Bland, Pamela Rose, Mark Horton y Richard Evershed

2005 Gas Chromatographic, Mass Spectrometric and Stable Carbon Isotopic Investigations of Organic Residues of Plant Oils and Animal Fats Employed as Illuminants in Archaeological Lamps from Egypt. Analyst 130:860-871.
Cornely, Francisco

1940 Nuevos descubrimientos arqueológicos en la provincia de Coquimbo. Boletín del Museo Nacional de Historia Natural 18:9-16.

1951 Cultura Diaguita Chilena. Revista Chilena de Historia Natural 51-53:119-262

1956 Cultura Diaguita Chilena y cultura de El Molle. Editorial El Pacífico, Santiago.

Cueto, Manuel, Aylen Caparelli, Laura Ciampagna, Matías Paunero y Alicia Castro

2010 Prácticas postcolecta y material leñoso: análisis de residuos y huellas microscópicas de origen vegetal, sobre artefactos de roca tallada, utilizados en contextos experimentales. En Actas del XVII Congreso Nacional de Arqueología Argentina, editado por Roberto Bárcena y Horacio Chiavazza, Tomo III, pp. 1205-1210. Mendoza. de Souza, Patricio

2004 Tecnologías de proyectil durante los períodos Arcaico y Formativo en el Loa superior (Norte de Chile): a partir del análisis de puntas líticas. Chungará, Revista de Antropología Chilena Volumen Especial:61-76.

Dillon, Michael

2005 The Solanaceae of the Lomas Formations of Coastal Peru and Chile. Monographs in Systematic Botany from the Missouri Botanical Garden 104:131-156.

Dougherty, Bernard

1972 Las pipas de fumar arqueológicas de la Provincia de Jujuy. Relaciones de la Sociedad Argentina de Antropología VI:83-89

Dupont, Robert, y Werner Baumgartner

1995 Drug Testing by Urine and Hair Analysis: Complementary Features and Scientific Issues. Forensic Science International 70:63-76.

Echeverría, Javier, y Hermann M. Niemeyer

2013 Nicotine in the Hair of Mummies from San Pedro de Atacama (Northern Chile). Journal of Archaeological Science 40:3561-3568.

Echeverría, Javier, María Teresa Planella y Hermann M. Niemeyer

2014 Nicotine in Residues of Smoking Pipes and other Artifacts of the Smoking Complex from an Early Ceramic Period Archaeological Site in Central Chile. Journal of Archaeological Science 44:55-60.

Elferink, Jan

1983 The Narcotic and Hallucinogenic Use of Tobacco in Pre-Columbian Central America. Journal of Ethnopharmacology 7:111-122.

Evershed_Richard

1993 Biomolecular Archaeology and Lipids. World Archaeology 25:74-93

Fernández Distel, Alicia

1980 Hallazgos de pipas en complejos precerámicos del borde de la Puna jujeña (República Argentina) y el empleo de alucinógenos por parte de las mismas culturas. Estudios Arqueológicos 5:55-75.

Gallardo, Francisco

1993 La sustancia privilegiada: Turbantes, poder y simbolismo en el Formativo del norte de Chile. En Identidad y prestigio en Los Andes, editado por José Berenguer, pp. 9-15. Museo Chileno de Arte Precolombino, Santiago.

Gallardo, Francisco, y Patricio de Souza

2008 Rock Art, Modes of Production, and Social Identities during the Early Formative Period in the Atacama Desert (Northern Chile). En Archaeologies of Art. Time, Place, and Identities, editado por Inés Sanz, Danae Fiore y Sally May, pp. 79-97. Left Coast Press Inc., Walnut Creek. 
Gallardo, Francisco, y Hugo Yacobaccio

2005 Wild or Domesticated? Camelids in Early Formative Rock Art of the Atacama Desert (Northern Chile). Latin American Antiquity 16:115-130.

Gili, Francisca

2014 La práctica fumatoria en el salar de Atacama durante el período Formativo. Tesis de Maestría en Arqueología inédita, Universidad Católica del Norte y Universidad de Tarapacá.

Gili, Francisca, y Álvaro Villagrán

2011 El caso de estudio de una pipa del sitio Socaire 22, San Pedro de Atacama, Chile. En II Congreso Latinoamericano de Arqueometría, pp. 443-452. Lima, Perú.

Goodspeed, Thomas H.

1954 The Genus Nicotiana. Origins, Relationships and Evolution in its Species in the Light of Their Distribution, Morphology and Cytogenetics. Chronica Botanica Company, Waltham, Massachusetts.

Haslam, Michael

2004 The Decomposition of Starch Grains in Soils: Implications for Archaeological Residue Analyses. Journal of Archaeological Science 31:1715-1734.

Janiger, Oscar, y Marlene Dobkin

1973 Suggestive Hallucinogenic Properties of Tobacco. Medical Anthropology Newsletter 4 (4):6-11.

1976 Nicotiana an Hallucinogen? Economic Botany 30:295297.

Johnston, Ivan

1929 Papers on the Flora of Northern Chile. Contributions from the Gray Herbarium of Harvard University 85:1-172.

Knudson, Kelly, William Pestle, Christina Torres-Rouff y Gonzalo Pimentel

2012 Assessing the Life History of an Andean Traveler through Biogeochemistry: Stable and Radiogenic Isotope Analyses of Archaeological Human Remains from Northern Chile. International Journal of Osteoarchaeology 22:435451.

Koirala, Bikul, y Jeffrey Rosentreter

2009 Examination of Prehistoric Artifacts via Fatty Acid Methyl Ester (FAME) Techniques Using Modern Environmental Stewardship. Journal of Archaeological Science 36:1229-1242

Korstanje, Alejandra

2010 Producción y consumo agrícola en el Valle del Bolsón (1992-2005). En Arqueología de la agricultura: casos de estudio en la región andina argentina, editado por Alejandra Korstanje y Marcos Quesada, pp. 48-75. Magna, Tucumán.

Korstanje, Alejandra, y Pilar Babot

2007 A Microfossil Characterization from South Andean Economic Plants. En Plants, People and Places: Recent Studies in Phytholithic Analysis, editado por Marco Madella y Debora Zurro, pp. 41-72. Oxbow Books, Cambridge.

Larraín, Horacio

1974 Demografía y asentamientos de los pescadores costeros del Sur peruano y norte chileno, según informes del cronista Antonio Vásquez de Espinoza (1617-18). Norte Grande 1:55-80.

1978 Análisis demográfico de las comunidades de pescadores changos del Norte de Chile en el Siglo XVI. Tesis Master of Arts inédita, Department of Anthropology, State University of New York.

Latcham, Ricardo

1909 El comercio precolombino en Chile y otros países de América. Anales de la Universidad de Chile 125:241284.
1940 Observaciones acerca de la cultura "El Molle". Boletín del Museo Nacional de Historia Natural 18:1721.

Le Paige, Gustavo

1964 El Precerámico en la cordillera Atacameña y los cementerios del Período Agro-Alfarero de San Pedro de Atacama. Anales de la Universidad del Norte 3:1-275.

1974 El yacimiento de Tchaputchayna. EstudiosAtacameños 2:57-71.

Llagostera, Agustín

1979 9,700 Years of Maritime Subsistence on the Pacific: An Analysis by Means of Bioindicators in the North of Chile. American Antiquity 44:309-324.

1990 La navegación prehispánica en el Norte de Chile: bioindicadores e inferencias teóricas. Chungará, Revista de Antropología Chilena 24-25:37-51.

Loy, Tom

1994 Methods and Analysis of Starch Residues of Prehistoric Stone Tools. En Tropical Archaeobotany: Application and New Development, editado por Jon Hater, pp.86114. Routledge, New York.

McRostie, Virginia

2010 Primeros análisis de microfósiles en la Puna Salada occidental. Una aproximación a la utilización y cambio morfológico de los morteros de la Quebrada de Tulán durante la transición Arcaico-Formativo. Sur de Salar de Atacama, II Región, Chile. En Actas del XVII Congreso Nacional de Arqueología Chilena. Tomo II:1247-1253. Valdivia.

Madella, Marco, Anne Alexandre y Terry Ball

2005 International Code for Phytolith Nomenclature 1.0. Annals of Botany 96:253-260.

Marticorena, Clodomiro, Oscar Matthei, Roberto Rodríguez, Mary Kalin Arroyo, Melica Muñoz, Francisco Squeo y Gina Arancio

1998 Catálogo de la flora vascular de la Segunda Región. Gayana Botánica 55:23-83.

Mostny, Grete

1964 Arqueología de Taltal: epistolario de Augusto Capdeville con Max Uhle y otros. DIBAM, Fondo Histórico y Bibliográfico José Toribio Medina, Santiago.

Montt, Indira

2002 Faldellines del Período Formativo en el Norte Grande: Un ensayo acerca de la historia de su construcción visual. Estudios Atacameños 23:7-22.

Musaubach, Gabriela, y Mónica Berón

2012 Cocinando en ollas en la Pampa occidental. Datos de la etnohistoria, el registro arqueológico y la arqueobotánica. En Las manos en la masa. Arqueologías, antropologías e historias de la alimentación en Suramérica, editado por Pilar Babot, María Marschoff y Francisco Pazzarelli, pp. 599-621. Universidad de Córdoba. Córdoba.

Niemeyer, Hans, Miguel Cervellino y Gastón Castillo

1989 Los primeros ceramistas del Norte Chico: Complejo El Molle. En Culturas de Chile. Prehistoria. Desde sus orígenes hasta los albores de la Conquista, editado por Jorge Hidalgo, Virgilio Schiapacasse, Hans Niemeyer, Carlos Aldunate, e Iván Solimano, pp. 227-264. Editorial Andrés Bello, Santiago.

Núñez, Lautaro

1971 Secuencia y cambio en los asentamientos humanos de la desembocadura del Río Loa, en el Norte de Chile. Boletín de la Universidad de Chile 112:2-25.

2005 La naturaleza de la expansión aldeana durante el Formativo tardío en la cuenca de Atacama. Chungará, Revista de Antropología Chilena 37:165-193. 
Núñez, Lautaro, Isabel Cartajena, Carlos Carrasco y Patricio de Souza

2005 El templete de Tulán y sus relaciones formativas panandinas (Norte de Chile). Boletín del Instituto Francés de Estudios Andinos 34:299-320.

Núñez, Lautaro, Isabel Cartajena, Carlos Carrasco, Patricio de Souza y Martin Grosjean

2006 Emergencia de comunidades pastoralistas formativas en el sureste de la Puna de Atacama. Estudios Atacameños 32:93-117.

Orellana, Mario

1963 La cultura San Pedro. Estudio arqueológico de la Cultura agro-alfarera precolombina de la zona de San Pedro de Atacama. Arqueología Chilena 3:1-42.

1991 Contextos culturales tempranos de Toconao Oriente. Diálogo Andino 10:22-46.

Pazzarelli, Francisco

2011 Nota: una aproximación a la transformación de recursos en Piedras Blancas (Ambato, Catamarca, s X-XI D.C.) desde los análisis químicos. Relaciones de la Sociedad Argentina de Antropología XXXVI:331-336.

Pearsall, Deborah, y Dolores Piperno

1993 Current Research in Phytolith Analysis: Applications in Archaeology and Paleoecology. University of Pennsylvania Museum, Philadelphia.

Pestle, William, Christina Torres-Rouff, Francisco Gallardo, Benjamín Ballester y Alejandro Clarot

2015 Mobility and Exchange among Marine HunterGatherer and Agropastoralist Communities in the Formative Period Atacama Desert. Current Anthropology, 56(1):121-133.

Pimentel, Gonzalo

2012 Redes viales prehispánicas en el Desierto de Atacama: Viajeros, movilidad e intercambio. Tesis Doctoral inédita, Universidad Católica del Norte y Universidad de Tarapacá Instituto de Investigaciones Arqueològicas y Museo R.P. Gustavo Le Paige S.J.

Pimentel, Gonzalo, Charles Rees, Patricio de Souza y Lorena Arancibia

2011 Viajeros costeros y caravaneros. Dos estrategias de movilidad en el Período Formativo del Desierto de Atacama, Chile. En Ruta. Arqueología, Historia y Etnografía del Tráfico Sur Andino, editado por Lautaro Núñez y Axel Nielsen, pp. 43-81. Encuentro Grupo Editor, Córdoba.

Piperno, Dolores

2006 Phytoliths. A Comprehensive Guide for Archaeologists and Paleoecologists. AltaMira Press, Lanham, Maryland, and Oxford.

Piperno, Dolores, e Irene Holst

1998 The Presence of Starch Grains on Prehistoric Stone Tools from the Humid Neotropics: Indications of Early Tuber Use and Agriculture in Panama. Journal of Archaeological Science 25:765-776.

Planella, María Teresa, Luciana Quiroz, Carolina Belmar y Virginia McRostie

2009 Explorando el bosque esclerófilo: fitolitos y almidones de la flora nativa de Chile central. En Resúmenes del XVIII congreso nacional de arqueología Chile, pp. 201203. LOM, Valparaíso.

Planella, María Teresa, Gabriela Santander y Virginia McRostie 2011 Estudio morfo-tecnológico y análisis de microfósiles en bloques con piedras tacitas en Chile Central. En $D e$ las muchas historias entre las plantas y las gentes, editado por Sneider Rojas-Mora y Carolina Belmar. British Archaeological Reports, Oxford.
Planella, María Teresa, Katherine Collao-Alvarado, Hermann M. Niemeyer y Carolina Belmar

2012 Morfometría comparada de semillas de Nicotiana (Solanaceae) e identificación de semillas carbonizadas provenientes de un sitio arqueológico en Chile Central. Darwiniana 50:207-217.

Quiroz, Luciana, Carolina Belmar, María Teresa Planella, Rodrigo Mera y Doina Munita

2012 Estudio de microfósiles de residuos adheridos en pipas cerámicas del sitio villa JMC-1 Labranza, Región de la Araucanía. Magallania 40:249-261.

Rafferty, Sean

2002 Identification of Nicotine by Gas Chromatography/ Mass Spectroscopy Analysis of Smoking Pipe Residue. Journal of Archaeological Science 29:897-907.

2006 Evidence of Early Tobacco in Northeastern North America? Journal of Archaeological Science 33:453458.

Rafferty, Sean, Igor Lednev, Kelly Virkler y Zuzana Chovanec

2012 Current Research on Smoking Pipe Residues. Journal of Archaeological Science 39:1951-1959.

Rees, Charles

1999 Elaboración, distribución y consumo de cuentas de malaquita y crisocola durante el Período Formativo en la Vega de Turi y sus inmediaciones, subregión del Salado, Norte de Chile. En Los tres reinos, prácticas de recolección en el cono sur de América, editado por Carlos Aschero, pp. 105-131. Instituto de Arqueología y Museo, Universidad Nacional de Tucumán.

Rees, Charles, y Patricio de Souza

2004 Producción lítica durante el Período Formativo en la cuenca alta del río Salado. Chungará, Revista de Antropología Chilena, Volumen Especial:619-639.

Ricardi, Mario

1957 Fitogeografía de la costa del departamento de Taltal. Boletín de la Sociedad Biológica de Concepción 32:310.

Rosso, Cintia, y Romina Spano

2005-2006 Evidencias del uso de alucinógenos en pipas halladas en dos sitios tempranos de los Valles Calchaquíes. Arqueología 13:79-99.

Rundel, Philip, Michael Dillon, Beatriz Palma, Harold Mooney, Sherry Glumon y James Ehleringer

1991 The Phytogeography and Ecology of the Coastal Atacama and Peruvian Desert. Aliso 13(1):1-49.

Schiffer, Michael

1972 Archaeological Context and Systemic Context. American Antiquity 37 (2):156-165.

1983 Toward the Identifican of Formation Processes. American Antiquity 48(4):675-706.

Sinclaire, Carole

2004 Prehistoria del Período Formativo en la cuenca alta del río Salado (región del Loa Superior: Un estado de la cuestión. Chungará, Revista de Antropología Chilena, Volumen Especial:619-639.

Spahni, Jean

1967 Recherches archéologiques à l'embouchure du Rio Loa (Côte du Pacifique-Chili). Journal de la Société des Américanistes LVI (I):181-239.

Tarragó, Myriam

1989 Contribución al conocimiento arqueológico de las poblaciones de los oasis de San Pedro de Atacama en relación con los otros pueblos puneños, en especial el sector septentrional del Valle de Calchaquí. Tesis Doctoral inédita, Facultad de Humanidades y Arte, Universidad Nacional del Rosario. 
Thomas, Carlos, Antonia Benavente, Isabel Cartajena y George Serracino

1995 Topater, un cementerio temprano: una aproximación simbólica. Hombre y Desierto 9:159-170.

Thomas, Carlos, Antonia Benavente y Claudio Massone 1989-1990 Investigaciones arqueológicas de la región del Loa Medio. Revista Chilena de Antropología 8:53-61.

Torres, Constantino

1996 Archaeological Evidence for the Antiquity of Psychoactive Plant Use in the Central Andes. Ann. Mus. civ. Rovereto 11:291-326.

1998 Psychoactive Substances in the Archaeology of Northern Chile and NW Argentina. A Comparative Review of the Evidence. Chungará, Revista de Antropología Chilena 30 (1):49-63.

Torres, Constantino, David Repke, Kelvin Chan, Dennis McKenna, Agustín Llagostera y Richard Schultes

1991 Snuff Powders from Pre-Hispanic San Pedro de Atacama: Chemical and Contextual Analysis. Current Anthropology 32 (5):640-649.

Torres-Rouff, Christina, William Pestle y Francisco Gallardo 2012 Eating Fish in the Driest Desert in the World: Osteological and Biogeochemical Analyses of Human Skeletal Remains from the San Salvador Cemetery, North Chile. Latin American Antiquity 23:51-69.

Torres-Rouff,Cristina, Gonzalo Pimentel y Mariana Ugarte

2012 ¿Quiénes viajaban? Investigando la muerte de viajeros prehispánicos en el Desierto de Atacama (ca. 800 a.C.1536 d.C.). Estudios Atacameños 43:167-186.

True, Delbert

1975 Early Maritime Cultural Orientations in Prehistoric Chile. En Maritime Adaptations of the Pacific, editado por Richard Casteel y George Quimby, pp. 89-143. Mouton Publishers, París.

Tushingham, Shannon, Dominique Ardura, Jelmer Eerkens, Mine Palazoglu, Sevini Shahbaz y Oliver Fiehn

2013 Hunter-Gatherer Tobacco Smoking: Earliest Evidence from the Pacific Northwest Coast of North America. Journal of Archaeological Science 40:1397-1407.
Uribe, Mauricio

2009 El período Formativo de Tarapacá y su cerámica: Avances sobre complejidad social en la costa del Norte Grande de Chile (900 a.C.-800 d.C.). Estudios Atacameños 37:5-27.

Uribe, Mauricio, y Patricia Ayala

2004 La alfarería de Quillagua en el contexto formativo del Norte Grande de Chile (1000 a.C.-500 d.C.). Chungará, Revista de Antropología Chilena, Volumen Especial:585598.

Wells, Samuel

2000 American Drugs in Egyptian Mummies: A Review of the Evidence. Documento electrónico, http://www.celticnz.co.nz/Nazca/American\%20Drugs\%20in\%20Egyptian\%2 0Mummies.htm, accedido Mayo 14, 2014.

Westfall, Catherine

1993-1994 Pipas prehispánicas de Chile. Discusión en torno a su distribución y contexto. Revista Chilena de Antropología 12:123-161.

Wilbert, Johannes

1991 Does Pharmacology Corroborate the Nicotine Therapy and Practices of South American Shamanism? Journal of Ethnopharmacology 32:179-186.

\section{Notas}

1. Definimos el rango temporal del Formativo según los procesos acaecidos en el litoral y no siguiendo la secuencia tradicional de San Pedro de Atacama, en donde se ha planteado la existencia de un Período Medio que se encuentra ausente entre los cazadores-recolectores marinos (Ballester y Clarot 2014).

Submitted June 10, 2014; Revised October 24, 2014; Accepted February 5, 2015. 